\title{
OPTIMIZATION OF PROCESS PARAMETERS FOR SURFACE ROUGHNESS OF GFRP WITH AWJ MACHINING USING TAGUCHI AND GRA METHODS
}

\author{
Anil Kumar Dahiya ${ }^{1}$, Basanta Kumar Bhuyan ${ }^{2}$, Shailendra Kumar ${ }^{3}$ \\ ${ }^{1}$ Department of ME-FET, MRIIRS, Faridabad \& Department of MAE, \\ Maharaja Agrasen Institute of Technology, Delhi, India \\ ${ }^{2}$ Department of Mechanical Engineering- FET, MRIIRS, Faridabad, India. \\ ${ }^{3}$ Department of Mechanical Engineering, S. V. National Institute of Technology, Surat, India \\ Corresponding Author: Anil Kumar Dahiya, anilkrdahiya@mait.ac.in
}

\begin{abstract}
For machining of composites like glass fibre reinforced polymers, abrasive water jet machining is generally used. In the present paper, an experimental investigation is described which is focused on studying the influence of AWJM process parameters on surface roughness of machined samples. Four process parameters namely water pressure, traverse speed, stand-off distance and abrasive mass flow rate are considered in the present study. Taguchi technique is used for the design of experiments and analysis of variance (ANOVA) is performed to determine the significance of parameters. It is found that water pressure and traverse speed are the major significant parameters for influencing surface roughness. Surface roughness decreases with increase in water pressure and decrease in traverse speed. For surface roughness minimization Grey Relational Analysis (GRA) technique is used for multi optimization of process parameters and experimental results are analyzed using Grey Relational Grades (GRG).
\end{abstract}

Key words: AWJM, surface roughness, process parameters, Taguchi, ANOVA, GRG.

\section{INTRODUCTION}

Composites have a very prominent place in advanced engineering materials because of their better mechanical properties like high strength, low density, corrosion resistance, stiffness and impact strength. Composites give high value of strength to weight ratio as compared to conventional metals and other materials. Composites have wide applications in aerospace, transportation, construction, marine goods, sporting goods, and infrastructure sectors (Campbell, 2010). Glass fibre reinforced polymer (GFRP) composite is a fiber-reinforced polymer composite that is exceptionally strong and light. Abrasive water jet machining (AWJM) is a prominent non-traditional machining method for cutting of composites with enhanced kerf characteristics. In this method, a highspeed water jet comprising abrasive particles impinges on the workpiece surface to erode the desired material as shown in Figure 1. This machining method is preferred for heat-sensitive materials, since it generates no heat, harmful waste, and results in minimal stresses in the workpiece material. However, to get the maximum advantage, process parameters of AWJM should be optimized.

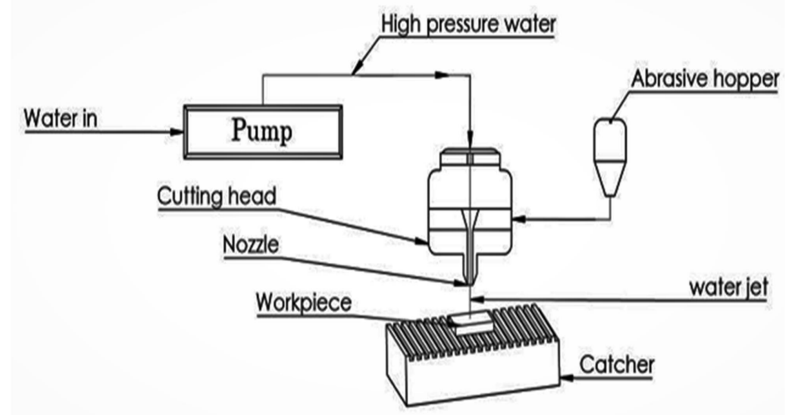

Fig. 1. AWJM setup

Many researchers have investigated various process parameters of AWJM and their impact on surface roughness $\left(\mathrm{R}_{\mathrm{a}}\right)$. Irina Wong et al. (2018) experimentally investigated the main significant parameters for minimum kerf ratio in hybrid carbon/glass fibre reinforcing polymers with AWJM. Dhanawade et al. (2016) experimentally investigated the influence of different variable parameters of AWJM on carbon epoxy composite and reported that traverse speed (TS) and water pressure (WP) are the main substantial factors for $\mathrm{R}_{\mathrm{a}}$ and kerf taper minimization. Mayuet Ares et al. (2019) experimentally investigated and optimized various parameters such as standoff distance (SOD), TS and 
abrasive mass flow rate (AMFR) for $\mathrm{R}_{\mathrm{a}}$ and kerf taper angle on CFRP composites with AWJM. Vigneshwaran et al. (2018) reported that $R_{a}$ improves for fibre reinforced composites using AWJ machining when traversing speed drops and water jet pressure increases. Banon et al. (2020) experimentally investigated surface quality at three different regions namely entry, central, and outflow, and observed that at the entry zone surface quality was most affected followed by the outflow zone. RSM technique was used for optimizing process parameters of carbon fibre reinforced thermoplastic matrix composite (CFRTP) and revealed that surface quality is influenced by AMFR and hydraulic pressure and optimized parameters like hydraulic jet pressure, AMFR, and TS to produce good surface quality. Ruiz-Garcia et al. (2019) experimentally investigated kerf width and surface quality of CFRP composite plate and aluminum alloy plate stack (UNS A97075) with AWJM and studied the influence of traverse feed rate, AMFR, and hydraulic pressure experimentally and revealed the conditions to minimize the deviation, defects, and damage in straight cut and hole. Sambruno et al. (2019) used AWJM to optimize the process parameters for kerf taper of carbon fibre reinforced thermoplastic (CFRTP) and found that hydraulic pressure of $3400 \mathrm{bar}$, feed rate $100 \mathrm{~mm} / \mathrm{min}$, and AMFR$340 \mathrm{~g} / \mathrm{min}$ are the best combination of parameters for minimizing kerf taper. Ravikant et al. (2021) optimized the various parameters of EN31steel using AWJ machining for $\mathrm{R}_{\mathrm{a}}$, machining time and hardness. Arunkumar and Murugaranjan (2021) experimentally examined the influence of input parameters on $R_{a}$ of chicken feather fibre-reinforced composite. Input parameters were optimized using artificial neural network and RSM techniques.

In the present experimental work, investigation is performed to study influence of AWJM process parameters on surface roughness of machined GFRP composite. Taguchi's L16 orthogonal array is used for design of experiments and GRA is applied for the optimization of process parameters.

\section{EXPERIMENTAL PLAN}

In this study, $R_{a}$ is investigated based on AWJM process parameters namely water pressure transverse speed, stand-off distance and abrasive mass flow rate. Three-axis flying arm CNC AWJ machine (Model -Yongda YD3020) is used to machine GFRP composite. L-16 orthogonal array was chosen based on selected parameters, and a total of 16 experiments in different combinations were carried out for design of experiment. ANOVA analysis is used to evaluate the influence of input factors on response. For multi-performance optimization, grey relational analysis technique is used. Glass fibre reinforced polymer workpiece with dimensions of $500 \times 40 \times 20 \mathrm{~mm}$ is used for this study. The size and machined workpiece for $\mathrm{Ra}$ are shown in Figure 2 (a) and 2(b). Garnet of grit size 80 was chosen as an abrasive for the experiments, because of its wide range of industrial applications, availability, and low cost.

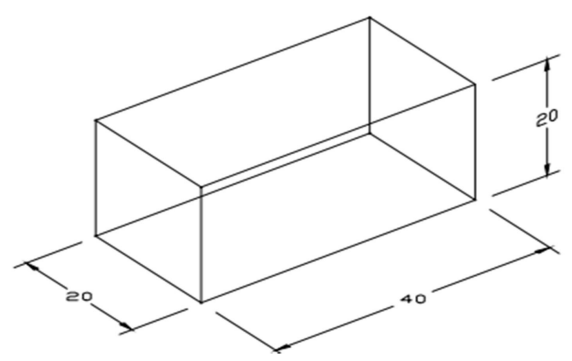

Fig. 2 (a). Size of machined workpiece sample

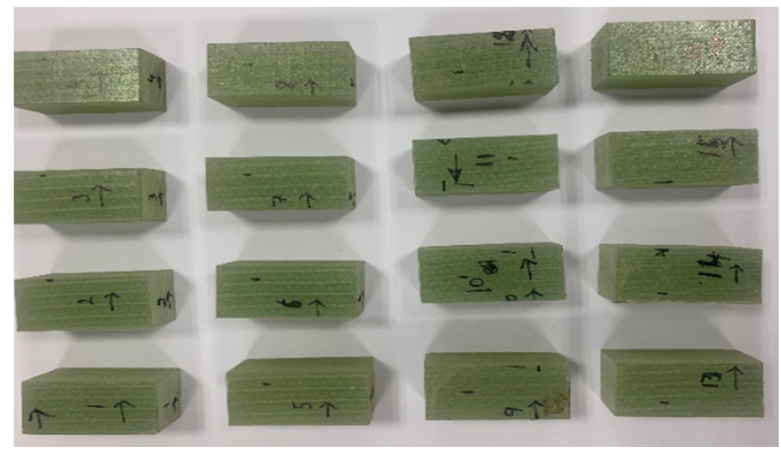

Fig. 2 (b). Machined samples for surface roughness

For the current study four key parameters namely WP, SOD, TS and AMFR have been selected based on the literature review. Other parameters like grit size of abrasive \#80, impact angle $90^{\circ}$, nozzle diameter $0.76 \mathrm{~mm}$, orifice diameter $0.25 \mathrm{~mm}$ and focusing tube length $70 \mathrm{~mm}$ were maintained constant throughout the experimental work. Table 1 depicts the variable parameters with their levels. Design of experiments based on L-16 orthogonal array is given in Table 2 .

Table 1. Levels of process parameters

\begin{tabular}{|c|c|c|c|c|c|}
\hline Variable Parameters & Unit & 1 & 2 & 3 & 4 \\
\hline WP: Water Pressure & $\mathrm{MPa}$ & 200 & 250 & 300 & 350 \\
\hline TS: Traverse Speed & $\mathrm{mm} / \mathrm{min}$ & 50 & 100 & 150 & 200 \\
\hline SOD : Standoff distance & $\mathrm{mm}$ & 1 & 2 & 3 & 4 \\
\hline AMFR: Abrasive mass flow rate & $\mathrm{g} / \mathrm{min}$ & 200 & 400 & 600 & 800 \\
\hline
\end{tabular}


Table 2. Design of experiment using L-16 orthogonal array

\begin{tabular}{|c|c|c|c|c|}
\hline Exp. No. & WP (MPa) & $\mathrm{SOD}(\mathrm{mm})$ & $\mathrm{TS}(\mathrm{mm} / \mathrm{min})$ & $\operatorname{AMFR}(\mathrm{g} / \mathrm{min})$ \\
\hline 1 & 200 & 1 & 50 & 200 \\
\hline 2 & 250 & 1 & 100 & 400 \\
\hline 3 & 300 & 1 & 150 & 600 \\
\hline 4 & 350 & 1 & 200 & 800 \\
\hline 5 & 200 & 2 & 100 & 600 \\
\hline 6 & 250 & 2 & 50 & 800 \\
\hline 7 & 300 & 2 & 200 & 200 \\
\hline 8 & 350 & 2 & 150 & 400 \\
\hline 9 & 200 & 3 & 150 & 800 \\
\hline 10 & 250 & 3 & 200 & 600 \\
\hline 11 & 300 & 3 & 50 & 400 \\
\hline 12 & 350 & 3 & 100 & 200 \\
\hline 13 & 200 & 4 & 200 & 400 \\
\hline 14 & 250 & 4 & 150 & 200 \\
\hline 15 & 300 & 4 & 100 & 800 \\
\hline 16 & 350 & 4 & 50 & 600 \\
\hline
\end{tabular}

The response is calculated in these experiments using a Mitutoyo SJ-210 ISO 1997 surface roughness tester, as shown in Figure 3. To assess roughness, the stylus is dragged horizontally across the work piece's surface. In this procedure, surface roughness is recorded at 3 three different areas $R_{a}(3 \mathrm{~mm}, 10 \mathrm{~mm}$ and $17 \mathrm{~mm}$ away from the top surface) and the average of these values is used for further analysis.

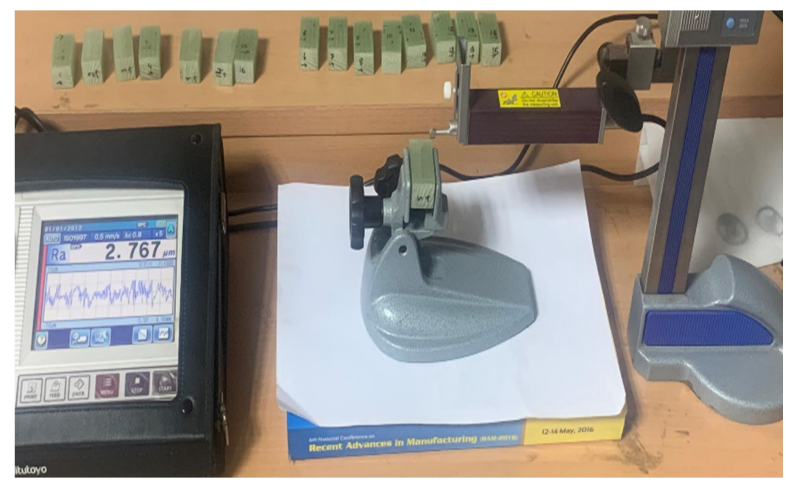

Fig. 3. Surface roughness tester

\section{RESULTS AND DISCUSSION}

After conducting experiments, the GRA approach is used to analyze the effect of process parameters on surface roughness and to minimize surface roughness, process parameters are optimized. The GRGs of surface roughness values in various regions (top, middle and bottom) are shown in Table 3 . Higher the value of the GRG, the closer the experimental findings are to the highly normalized.
GRA approach is used to optimise the input parameters namely SOD, TS, WP and AMFR to improve the $\mathrm{R}_{\mathrm{a}}$ of machined surface. The normalized values are calculated by using equation (1) (higher is better) and equation (2) (lower is better). For the $R_{a}$, 'lower is better' performance variable is used, as shown in equation no. (2).

$$
\begin{aligned}
X_{i j k}^{*} & =\left(\frac{X i j k-M i n_{J=1,2,3, \ldots q}^{X i j k}}{\max _{j=1,2,3, \ldots q}^{X i j k}-\operatorname{Min}_{j=1,2,3 \ldots q}^{X i j k}}\right) \\
X_{i j k}^{*} & =\left(\frac{\operatorname{Max}_{j=1,2,3 \ldots q}^{X i j k}-X_{i j k}}{\operatorname{Max}_{j=1,2,3, \ldots q}^{X i j k}-M i{ }_{j=1,2,3, \ldots q}^{X i j k}}\right)
\end{aligned}
$$

For $\mathrm{j}=1,2,3, \ldots . \mathrm{q}$.

The maximum of normalized value is obtained by equation (3) as given below (Panneerselvam, 2012).

$$
R=\operatorname{Max}_{\substack{i=1,2 \\ j=1,2, \ldots 9 \\ k=1,2,3}}\left(X_{i j k}^{*}\right)=1
$$

By using equation (4) difference of each normalized value and reference value is calculated

$$
\Delta \mathrm{ijk}=\left|X_{i j k}^{*}-R\right|
$$

Where $\mathrm{i}=1,2,3, \ldots, \mathrm{J}=1,2,3, \ldots$ and $\mathrm{k}=1,2,3, .$.

Grey relational coefficient (GRC) for each of normalized values, is calculated by using equation (5). 


$$
\xi_{i j k}=\left(\begin{array}{c}
\operatorname{Min}_{i=1,2, \ldots p}\left\{\Delta_{i j k}\right\}+\xi * \operatorname{Max}\left(\Delta_{i j k}\right) \\
j=1,2, \ldots q \\
k=1,2, \ldots r \\
\Delta_{i j k}+\xi * \operatorname{Max}_{i=1,2, \ldots p}\left(\Delta_{i j k}\right) \\
j=1,2, \ldots q \\
k=1,2, \ldots r
\end{array}\right)
$$

$$
\gamma_{j}=\frac{\sum_{i=1}^{2} \sum_{k=1}^{3} \xi_{i j k}}{2 \times 3}
$$

Where $\mathrm{j}=1,2,3, \ldots$

Grey relational grades (GRG) are computed using equation (6)

Table 3. GRGs method for $\mathrm{R}_{\mathrm{a}}$

\begin{tabular}{|c|c|c|c|c|c|c|c|c|c|}
\hline \multirow{2}{*}{$\begin{array}{l}\text { Exp. } \\
\text { No }\end{array}$} & \multirow{2}{*}{$\begin{array}{l}\mathrm{WP} \\
(\mathrm{MPa})\end{array}$} & \multirow{2}{*}{$\begin{array}{c}\mathrm{SOD} \\
(\mathrm{mm})\end{array}$} & \multirow{2}{*}{$\begin{array}{c}\mathrm{TS} \\
(\mathrm{mm} / \mathrm{min})\end{array}$} & \multirow{2}{*}{$\begin{array}{c}\text { AMFR } \\
(\mathrm{g} / \mathrm{min})\end{array}$} & \multicolumn{4}{|c|}{$\mathrm{R}_{\mathrm{a}}$ (microns) } & \multirow{2}{*}{ GRGs } \\
\hline 1 & 200 & 1 & 50 & 200 & 2.889 & 2.959 & 3.148 & 2.999 & 0.35157359 \\
\hline 2 & 250 & 1 & 100 & 400 & 2.373 & 3.11 & 2.892 & 2.792 & 0.384506874 \\
\hline 3 & 300 & 1 & 150 & 600 & 2.711 & 2.686 & 2.916 & 2.771 & 0.380187937 \\
\hline 4 & 350 & 1 & 200 & 800 & 2.317 & 2.215 & 2.512 & 2.348 & 0.44820729 \\
\hline 5 & 200 & 2 & 100 & 600 & 2.848 & 2.824 & 3.112 & 2.928 & 0.35955387 \\
\hline 6 & 250 & 2 & 50 & 800 & 2.447 & 2.755 & 2.425 & 2.542 & 0.422545716 \\
\hline 7 & 300 & 2 & 200 & 200 & 2.579 & 2.825 & 3.114 & 2.839 & 0.371874997 \\
\hline 8 & 350 & 2 & 150 & 400 & 2.088 & 1.821 & 2.359 & 2.089 & 0.50150215 \\
\hline 9 & 200 & 3 & 150 & 800 & 2.901 & 2.691 & 3.067 & 2.886 & 0.364435942 \\
\hline 10 & 250 & 3 & 200 & 600 & 3.051 & 2.748 & 3.189 & 2.996 & 0.351120404 \\
\hline 11 & 300 & 3 & 50 & 400 & 1.261 & 1.151 & 1.382 & 1.365 & 0.781045127 \\
\hline 12 & 350 & 3 & 100 & 200 & 1.341 & 1.19 & 1.402 & 1.411 & $\theta .756589648$ \\
\hline 13 & 200 & 4 & 200 & 400 & 2.697 & 2.973 & 3.324 & 2.998 & 0.352334237 \\
\hline 14 & 250 & 4 & 150 & 200 & 2.712 & 2.58 & 2.878 & 2.723 & 0.386466372 \\
\hline 15 & 300 & 4 & 100 & 800 & 2.064 & 2.041 & 2.432 & 2.179 & 0.482424849 \\
\hline 16 & 350 & 4 & 50 & 600 & 1.021 & 0.704 & 1.401 & 1.342 & 0.789696425 \\
\hline
\end{tabular}

Table 4. Average GRG for each level

\begin{tabular}{|c|c|c|c|c|}
\hline & \multicolumn{4}{|c|}{ Average GRGs } \\
\hline LEVEL & WP $(\mathrm{MPa})$ & SOD $(\mathrm{mm})$ & TS $(\mathrm{mm} / \mathrm{min})$ & AMFR $(\mathrm{g} / \mathrm{min})$ \\
\hline 1 & 0.356974 & 0.391119 & $\mathbf{0 . 5 8 6 2 1 5}$ & 0.466626 \\
\hline 2 & 0.38616 & 0.413869 & 0.495769 & $\mathbf{0 . 5 0 4 8 4 7}$ \\
\hline 3 & 0.503883 & $\mathbf{0 . 5 6 3 2 9 8}$ & 0.408148 & 0.47014 \\
\hline 4 & $\mathbf{0 . 6 2 3 9 9 9}$ & 0.50273 & 0.380884 & 0.429403 \\
\hline
\end{tabular}

Table 5. ANOVA table for GRG of $\mathrm{R}_{\mathrm{a}}$

\begin{tabular}{|c|c|c|c|c|c|c|c|}
\hline Source & DOF & Seq SS & Contribution & Adj SS & Adj MS & F-Value & Remarks \\
\hline WP $(\mathrm{MPa})$ & 3 & 0.17859 & $46.73 \%$ & 0.17859 & 0.059530 & 14.86 & Significant \\
\hline SOD $(\mathrm{mm})$ & 3 & 0.07651 & $20.02 \%$ & 0.07651 & 0.025505 & 6.37 & Insignificant \\
\hline TS $(\mathrm{mm} / \mathrm{min})$ & 3 & 0.10367 & $27.12 \%$ & 0.10367 & 0.034556 & 8.62 & Significant \\
\hline AMFR $(\mathrm{g} / \mathrm{min})$ & 3 & 0.01141 & $2.99 \%$ & 0.01141 & 0.003805 & 0.95 & Insignificant \\
\hline Error & 3 & 0.01202 & $3.15 \%$ & 0.01202 & 0.004007 & & \\
\hline Total & 15 & 0.38221 & $100.00 \%$ & & & & \\
\hline
\end{tabular}




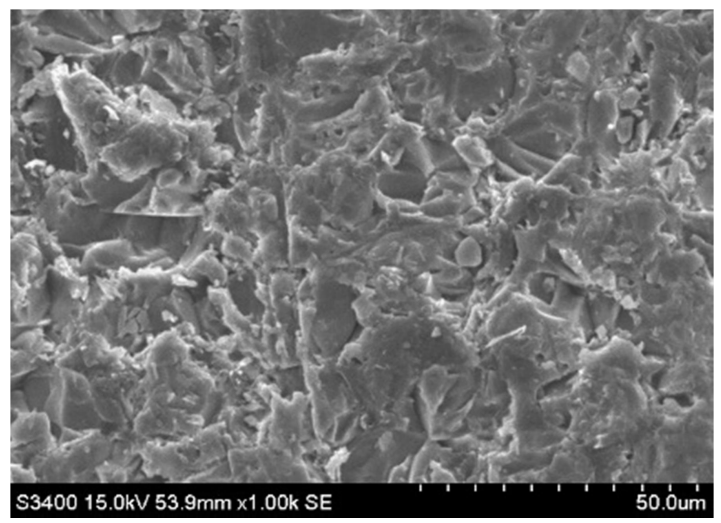

a)

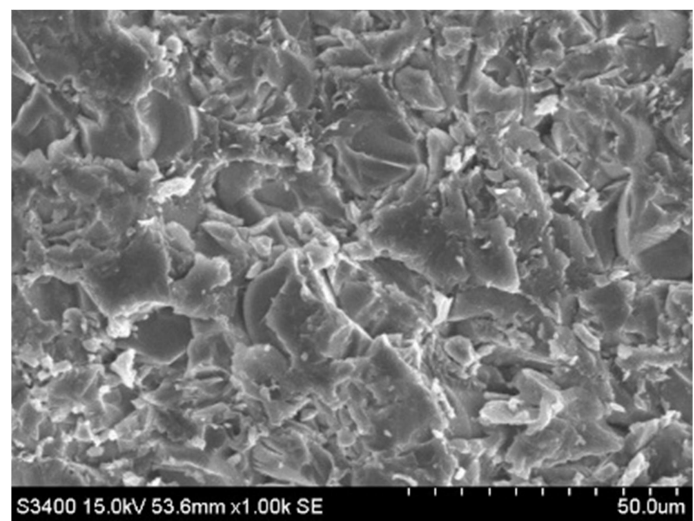

b)

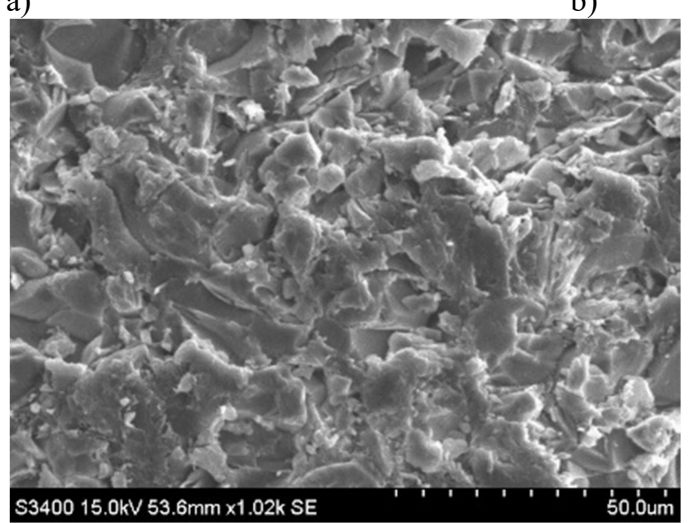

c)

Fig. 4. SEM images of machined sample (a-top, b-middle and c-bottom)

Table 4 lists the average GRGs for various combinations of parameters and levels. The higher values of average GRG shows the optimal levels of input parameters. Optimum values of input parameters for minimum surface roughness are WP $350 \mathrm{MPa}$, SOD - $3 \mathrm{~mm}$, TR - $50 \mathrm{~mm} / \mathrm{min}$, AMFR $400 \mathrm{~g} / \mathrm{min}$. Table 5 displays the results of ANOVA for GRG on $\mathrm{R}_{\mathrm{a}}$. ANOVA table clearly shows that WP and TS are the main significant parameters for $\mathrm{R}_{\mathrm{a}}$ and SOD and AMFR are insignificant parameters.

The mean GRG for each level of the machining parameters is calculated by averaging the GRGs and influence of process parameters on GRG is graphically depicted in Figure 5(a),(b),(c) and (d).

\section{(a) Effect of WP on GRG}

GRG is 0.35697441 at $200 \mathrm{MPa}$ pressure and increases to 0.623999 at $350 \mathrm{MPa}$ pressure, as shown in Figure 5(a). With increasing pressure, there is a significant rise in GRG. However, data demonstrates that when water pressure increases, $R_{a}$ decreases significantly. Increased pressure produces an increase in particle velocity at the nozzle outlet as well as particle fragmentation within nozzle. Size of the hitting particles is reduced as a result of this fragmentation. In addition, increasing the pump pressure increases the kinetic energy of the abrasive water jet. This extra kinetic energy slices the material with least amount of roughness.

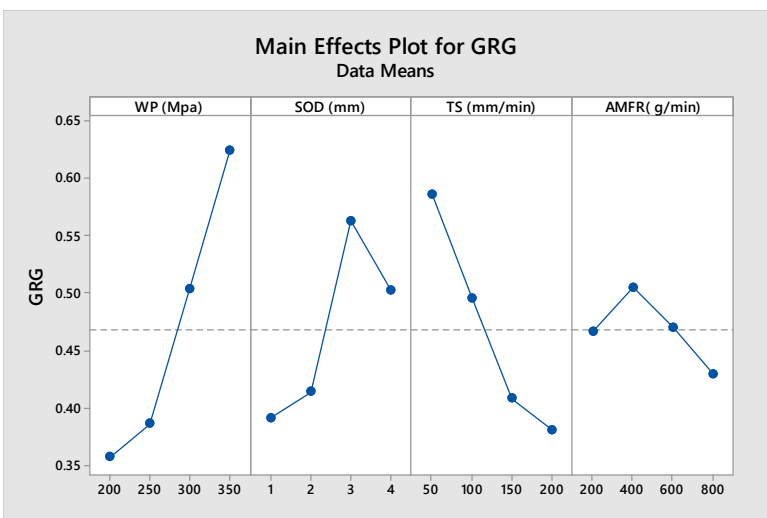

Fig. 5. Influence of process parameters on GRG (a) GRG vs WP, (b) GRG vs SOD, (c) GRG vs TS and (d) GRG vs AMFR

\section{(b) Effect of SOD on GRG}

Figure 5(b) shows that GRG is 0.391119 at $1 \mathrm{~mm}$ SOD, and it increases to 0.563298 when SOD is raised from $1 \mathrm{~mm}$ to $3 \mathrm{~mm}$; then decreases to 0.50273 at $4 \mathrm{~mm}$ SOD. However, when SOD increases, the roughness of the surface decreases. This might be because primary wavelength is shorter at lower SOD levels, but when SOD levels rise, primary wavelength increases. A high-speed jet accelerates abrasive 
particles. If $\mathrm{SOD}$ is increased above $3 \mathrm{~mm}, \mathrm{R}_{\mathrm{a}}$ increases, resulting in a decrease in jet velocity and as a result, jet kinetic energy. At high SOD, the water jet deviates as it exits from mixing tube, resulting in a reduction in kinetic energy and it causes a rough surface on the machined sample.

Table 6 . Average $\mathrm{R}_{\mathrm{a}}$ at an optimum set of parameters.

\begin{tabular}{|c|c|c|c|c|}
\hline \multirow{2}{*}{ Sample } & \multicolumn{3}{|c|}{ Surface Roughness (microns) } & \multirow{2}{*}{$\begin{array}{c}\text { Avg. Ra at } \\
\text { optimum set } \\
\text { of parameters }\end{array}$} \\
\hline & Top & Middle & Bottom & \\
\hline 1 & 1.305 & 1.103 & 1.441 & 1.283 \\
\hline 2 & 1.261 & 1.205 & 1.44 & 1.302 \\
\hline 3 & 1.298 & 1.167 & 1.42 & 1.295 \\
\hline
\end{tabular}

(c) Effect of TS on GRG

From Figure 5(c) the GRG is 0.586215 at a TS of 50 $\mathrm{mm} / \mathrm{min}$, and when the TS is gradually raised up to $200 \mathrm{~mm} / \mathrm{min}$, the GRG is 0.380884 , as shown in Figure 5(c). This demonstrates that $\mathrm{R}_{\mathrm{a}}$ increases with increase in TS. The main reason for this is that raising the TS causes less overlapping of machining action and fewer abrasive particles strike on the surface, which results in increased roughness.

\section{(d) Effect of AMFR on GRG}

GRG is 0.466626 at $200 \mathrm{~g} / \mathrm{min}$ AMFR increased to 0.504847 at $400 \mathrm{~g} / \mathrm{min}$. GRG was reduced to 0.429403 at $800 \mathrm{~g} / \mathrm{min}$. There is a minor change in GRG when AMFR increases as shown in Figure 5(d). Because the main function of abrasives is to cut material, therefore higher the abrasive flow rate, greater will be the cutting ability of the jet. However, at greater abrasive flow rates, abrasives collide with each other and lose kinetic energy, and it results in increased $R_{a}$ value. Figure 5 depicts that major influencing parameters for the $\mathrm{R}_{\mathrm{a}}$ are WP and TS. A smoother surface is produced at lower TS and higher WP. SOD and AMFR are insignificant parameters for $\mathrm{R}_{\mathrm{a}}$.

Figure 4 depicts the SEM images of AWJ machined surface of GFRP composites, as well as the changes that occurred throughout the machining process. Three different sections may be seen on the machined surface: the damaged top region (jet entrance), the middle smooth region, and the bottom region (rough and uncut) at jet exit. During AWJM, some of the kinetic energy of AWJ is used to erode material from the top area as AWJ impinges on the workpiece material. AWJ loses kinetic energy throughout this degradation process. In addition, a jet with lesser kinetic energy tends to deflect upward, parallel to the cutting plane. At the jet exit, this deflection creates a rough surface with striations.

\section{Predicted grey relation grade:}

Predicted grey relational grade $=\mathrm{A} 4+\mathrm{B} 3+\mathrm{C} 1+\mathrm{D} 3-3 \mathrm{~T}(7)$

where $\mathrm{T}$ is overall average of GRC

$=0.623999+0.563298+0.586215+0.504847-3 *$

0.467754

$=0.875097$

Higher values of GRGs shows optimum levels of input parameters. Confirmation tests are also carried out at optimum parameters (SOD-3mm, WP -350 $\mathrm{MPa}, \mathrm{TS}-50 \mathrm{~mm} / \mathrm{min}$ and AMFR - $400 \mathrm{~g} / \mathrm{min}$ ). Confirmation results shows that surface roughness is minimum with the optimum set of parameters. Table 6 shows the results of the confirmation test.

\section{CONCLUSIONS}

This paper described the experimental work focused on studying the influence of process parameters on surface roughness of GFRP composite machined by AWJM. Optimization of process parameters has been performed using GRA to minimize surface roughness.

TS and WP are the major parameters for influencing surface roughness. Surface roughness decreases with increase in WP and decrease in TS. SOD and AMFR are the minor substantial parameters for surface roughness. The experimental findings for the optimum parameters demonstrate a significant increase in surface finish. The results of the confirmation tests indicate that GFRP material may be successfully cut by AWJM with minimum surface roughness.

\section{REFERENCES}

1. Campbell, F. C., (2010). Introduction to Composite Materials, Structural Composite, Materials, ASM International, USA.

2. Irina Wong M. M., Azmi, A. I., Lee, C. C., Mansor, A. F., (2018). Kerf taper and delamination damage minimization of FRP hybrid composites under abrasive water-jet machining, Int. J. Adv. Manuf. Technol., 94, 1727-1744.

3. Dhanawade, A., Kumar, S., Kalmekar, R. V., (2016). Abrasive Water Jet Machining of Carbon Epoxy Composite, Def. Sci. J., 66 (5), 522-528. DOI : 10.14429/dsj.66.9501

4. MayuetAres, P. F., Mata, F.G., Ponce, M. B., Gomez, J.S., (2019) Defect Analysis and Detection of Cutting Regions in CFRP Machining Using AWJM. Materials, 12(24), 1-15. https://doi.org/10.3390/ma12244055

5. Vigneshwaran, S., Uthayakumar, M., Arumugaprabu, V, (2018). Abrasive water jet machining of fiber-reinforced composite materials, J. Reinf. Plast. Compos., 37(4), 230-237.

6. Banon, F., Sambruno, A., Batista, M., Simonet, B., Salguero, J., (2020). Study of the surface quality of 
carbon fiber-reinforced thermoplastic matrix composite (CFRTP) machined by abrasive water jet (AWJM). Int. J. Adv. Manuf. Technol., 107, 32993313.

7. Ruiz-Garcia, Raul, Mayuet Ares, Pedro, VazquezMartinez, Juan, Salguero Gomez, Jorge, (2019). Influence of Abrasive Water jet Parameters on the Cutting and Drilling of CFRP/UNS A97075 and UNS A97075/ CFRP Stacks. Materials, 12(1), 107.

8. Sambruno Alejandro, Banon Fermin, Salguero Jorge, Simonet Bartolome, Batista Moises, (2019). Kerf Taper Defect Minimization Based on Abrasive Waterjet Machining of Low thickness Thermoplastic Carbon Fiber Composites C/TPU, Materials, 12(24), 1-17. DOI: $10.3390 / \mathrm{ma1} 2244192$

9. Panneerselvam, R., (2012). Research Methodology. 2nd Edition, PHI Learning Private Ltd.: New Delhi.

10. Ravi Kant, Dhami, Sukhdeep S., (2021). Investigating Process Parameters of Abrasive Water Jet Machine using EN31, Mater. Manuf. Process, 36(14), 1597-1603.

11. Arunkumar K., Murugarajan A., (2021). Influence of AWJM process parameters on the surface quality of chicken feather fiber reinforced composite. Mater. Manuf. Process, DOI: 10.1080/10426914.2021.1962534

Received: July 12, 2021 / Accepted: December 15, 2021 / Paper available online: December 20, 2021 (C) International Journal of Modern Manufacturing Technologies 